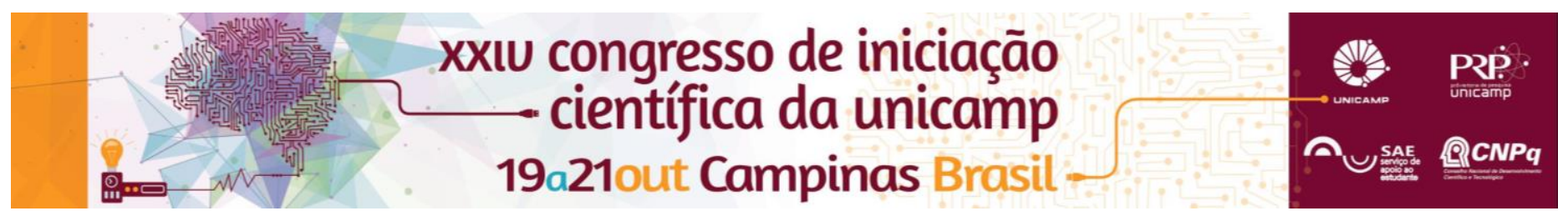

\title{
PRODUÇÃO JORNALÍSTICA POR ALUNOS DO ENSINO TÉCNICO: UMA EXPERIÊNCIA NO COLÉGIO TÉCNICO DE CAMPINAS
}

\author{
Felipe Leonel ${ }^{*}$, Laura Olivato Pereira, Luiza Bassan, Cristiane Maria Megid
}

\begin{abstract}
Resumo
Este projeto apresenta a experiência de estágio no jornal Conexão Cotuca, desenvolvido por alunos do Colégio Técnico de Campinas, e de elaboração dos jornais Crânio (na Escola Técnica Estadual Conselheiro Antônio Prado, de Campinas) e Impacto DJN (na Escola Estadual Dom João Nery, na mesma cidade). Ao longo desta pesquisa, foram estudados e discutidos conceitos de jornalismo, a organização de um jornal, as características dos diferentes textos jornalísticos e características do jornal online e digital. A partir disso e das observações da organização do Conexão Cotuca, seguiu-se à proposta de produção dos jornais online, planejados, organizados e produzidos pelos alunos das escolas mencionadas. Ao final deste estudo, as experiências foram analisadas e discutidas sob o ponto de vista de alunos do Ensino Médio, destacando o papel da produção jornalística em sua formação.
\end{abstract}

Palavras-chave: Jornalismo, Educação, Jornal Escolar, Jornal Online.

\section{Introdução}

Em 2015, os alunos autores deste projeto se inscreveram no Programa Institucional de Bolsas de Iniciação Científica - Ensino Médio (PIBIC-EM), coordenado pela Pró-Reitoria de Pesquisa da Unicamp em parceria com o CNPq, e foram designados para desenvolver pesquisas no Colégio Técnico da Unicamp (COTUCA), sob orientação da Profa. Dra. Cristiane Megid. Eles foram apresentados ao grupo de alunos do colégio que produz o jornal online Conexão Cotuca (conexaocotuca.com.br), com o objetivo de analisar sua organização e produzir outros dois jornais online: Jornal Crânio (jornalcranioetecap.blogspot.com.br), na Escola Técnica Estadual Conselheiro Antônio Prado (ETECAP), de Campinas e Impacto DJN (impactodjn3.webnode.com), na Escola Estadual Dom João Nery, na mesma cidade.

\section{Resultados e Discussão}

O jornal Conexão Cotuca, desenvolvido desde o início de 2015, sob orientação da professora Cristiane Megid e do professor André Pasti, já apresenta três edições publicadas, com apresentação de diferentes temas que foram pesquisados e discutidos pelos alunos que o integram. O aluno Felipe Leonel foi responsável pelo registro, análise e discussão das etapas de desenvolvimento do Conexão Cotuca.

O Jornal Crânio foi desenvolvido com essa mesma perspectiva, mas tendo como ponto de partida uma versão impressa, que já havia sido publicada antes do início deste projeto. A aluna LauraOlivato Pereira coordenou a organização de um grupo de alunos da ETECAP que foi responsável por reformular o jornal, diante da proposta de produzir uma versão online, feita pela professora Cristiane Megid. O novo suporte permitiu maior circulação ao Jornal Crânio, mas o projeto enfrentou dificuldades na organização dos alunos, o que foi minimizado com o apoio da professor Gisele Falcari. O jornal teve uma edição publicada em março de 2016 e, na sequência, os alunos decidiram realizer publicações quinzenais.

A aluna Luiza Bassan enfrentou também problemas para organização do grupo de alunos que produz o jornal
Impacto DJN. De acordo com as pesquisas da aluna, a escola Dom João Nery não teve outras experiências de
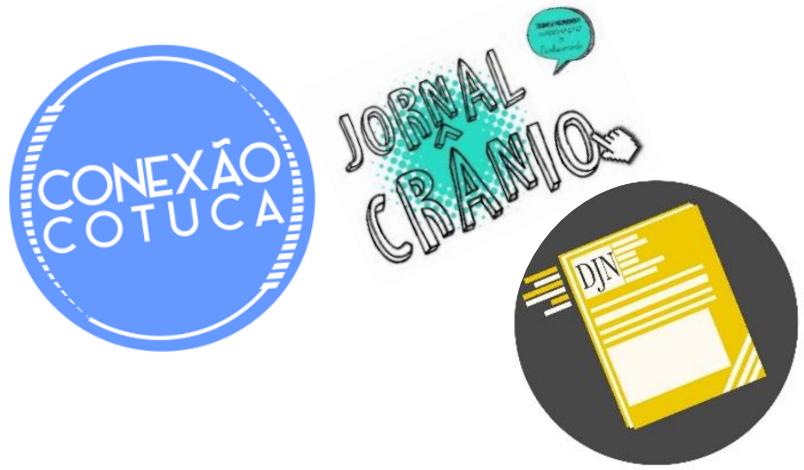

produção jornalística dos alunos, o que pode ter contribuído para as dificuldades encontradas. O grupo teve auxílio de professores de Língua Portuguesa e História, mas apenas na correção dos textos produzidos. A primeira edição foi lançada em junho de 2016.

As pesquisas sobre jornalismo e o estudo da organização do Conexão Cotuca foram fundamentais para que os outros dois jornais fossem elaborados. Percebeu-se que a participação de professores da escola onde o jornal é produzido é fundamenta para sua realização, indicando que o contexto escolar muitas vezes não permite a motivação do aluno por si só para essa tomada de voz.

\section{Conclusões}

Por meio deste trabalho, foi possível uma maior compreensão dos recursos linguísticos, principalmente aplicados à produção jornalística. Também foi possível que os alunos se envolvessem com problemas e responsabilidades éticas, próprios da produção de textos e da tomada de voz no ambiente em que se encontram, para que fosse possível incitar discussões e possibilidades de soluções para assuntos que permeiam seu cotidiano.

\section{Agradecimentos}

Ao CNPq, pelas bolsas e recursos concedidos. 